\title{
Determinants of Rural Women's Adaptation Measures to Climate Change in Yeki Woreda, Sheka Zone of South Western Ethiopia
}

\author{
Mohammed Ahmed $^{1 *} \quad$ Dereje Kifle $^{2} \quad$ Jemal Yousuf $^{2}(\mathrm{PhD})$ \\ 1.Tepi Agricultural Research Center, Ethiopian Institute of Agricultural Research, Ethiopia \\ 2.College of Agriculture and Environmental Science, Haramaya University, Ethiopia
}

\begin{abstract}
:
Climate change is a global challenge that burdens all of humanity. However, the world's poor, the majority of whom are women, are encumbered disproportionately. Adaptation is, therefore, considered as an important response, especially for those groups who are most exposed to and affected by its adverse effect. Hence, this study assessed the determinants of women's choices of adaptation strategies to climate change in Yeki Woreda, Sheka Zone of South Western Ethiopia using a multinomial logit model. A three-stage sampling procedure was followed in selecting 150 women farmers from three kebeles. The result revealed that productive labor force, farm size, farming experience, wealth status, access to climate information, credit service usage and extension visit were found to influence women's choice of adaptation strategies positively and significantly ( $\mathrm{P} \leq 10 \%)$. Therefore, development interventions, policies and supportive services should be designed at a different level to ensure effective access to climate information and affordable credit schemes for women households to enable them to plan and adapt in the face of the changing climate.
\end{abstract}

Keywords: Adaptation strategy, Climate change, MNL, Women, Yeki

DOI: $10.7176 / \mathrm{JAAS} / 72-01$

Publication date:May $31^{\text {st }} 2021$

\section{Introduction}

Climate change is one of the most serious global environmental threats facing mankind and expected to have a profound impact on people's livelihood by causing more severe weather events, rising sea levels and higher average temperature (IPCC, 2014). It has adversely affected agricultural productivity, availability, and use of water and health (Ziervogel et al., 2006).

Climate change is already having profound impacts in developing countries, especially in sub-Saharan Africa (SSA), with the increasing frequency and intensity of climate-related disasters, notably recurrent droughts, floods and erratic rainfall (IFAD, 2010). In Ethiopia, over the last decades, the onset and duration of rainfall seasons vary considerably inter-annually, causing frequent drought. Between the mid-1970s and late 2000s, Belg (Feb-May) and Meher (June-Sept) rainfall, based on quality-controlled station observations, decreased by $15-20 \%$ across parts of southern, south-western, and south-eastern Ethiopia (Mer, 2015; USGS et al., 2012).

Yeki, the study site, one of the most vulnerable Woreda in South Western parts of Ethiopia to the impacts of climate change due to landscape changes caused by the expansion of agricultural areas including coffee farms, tea plantations, and small-scale cultivated lands over the last four decades (Wiersum, 2010; Getachew, 2013). Consequently, the amount and predictability of rainfall is decreasing, and the temperature is increasing year after year, and resulting in crop production failure and a drastic rise in the number of people exposed to risks (USGS et al., 2012).

The impacts of climate change are not gender-neutral; women are vulnerable and most likely to be disproportionately affected by the adverse effects of climate change as they constitute the majority of the world poor and are more dependent on natural resources for their livelihood that is threatened by climate change (Dankelman, 2010). Moreover, they have unequal access and control over the productive resources and decisionmaking processes necessary to adapt to the changing climate (Kibria, 2016; Getachew, 2012; Ragasa et al., 2012). Adaptation is therefore considered as an important response, especially for those groups who are most exposed to and affected by its adverse effect.

Despite, few research has been conducted on women's adaptation strategies to climate change in Ethiopia, there is limited empirical evidence so far in the study area. Besides, most researches tend to represent farmers as a homogeneous group (Kidanu et al., 2016; Deressa et al., 2009; Maysoon, 2015; Urgessa et al., 2014). However, adaptation measures are very specific to a particular location and situation. Different characteristics will shape and affect their vulnerability and therefore are likely to respond differently to the changing climate (IPCC, 2011; Nellemann et al., 2011). This makes generalizations challenging on how climate change impacts women, what are, or should be, the adaptation strategies and priorities to meet the highly specific needs of rural women. The objective of the study is, therefore, to assess adaptation measures of rural women to climate change in Yeki Woreda, Sheka Zone of south-western Ethiopia. 


\section{Methodology}

\subsection{Description of the study area}

Geographically, the study district is located between $703^{\prime} \mathrm{N}$ latitude and 350, 0' E longitude in the south-western parts of Ethiopia. The maximum and minimum temperature of the area is $30^{\circ} \mathrm{C}$ and $15{ }^{\circ} \mathrm{C}$ respectively, with an altitude of $1200 \mathrm{~m}$ ASL. The mean annual rainfall of the area is $1591 \mathrm{~mm}$ which extends from April to December and the area is located under hot to warm humid lowland agroecology (TNSRC, 2015).

Yeki Woreda has a total population of 134,519, of whom 68,895 are men and 65,624 women; (CSA, 2007). The livelihood of the rural population is based on growing cereals (like maize, sorghum, rice, etc), enset, coffee, and spices (such as Turmeric, Black pepper, and cardamom). The land cover composition of the Woreda includes perennial agriculture (42.4\%), annual agriculture (34.3\%), and forests $(22.5 \%)$ (TCPE, 2010). Landholding sizes range from 0.5 ha to 5.5 ha, with a mean size of 1.3 ha of cropland, 0.6 ha coffee, 0.3 ha spices, 0.4 ha grazing and 0.3 ha plantations (Yeki Woreda Agricultural and Natural Resource, 2010). Forest cover in Yeki Woreda declined rapidly from to $73 \%$ by 1973 to $32 \%$ by 2010 forest as a result of the expansion of agricultural lands and settlements, and coffee farms. Consequently, the landscape changed from a forest dominated to non-forest dominated during the last four decades (Ibid).

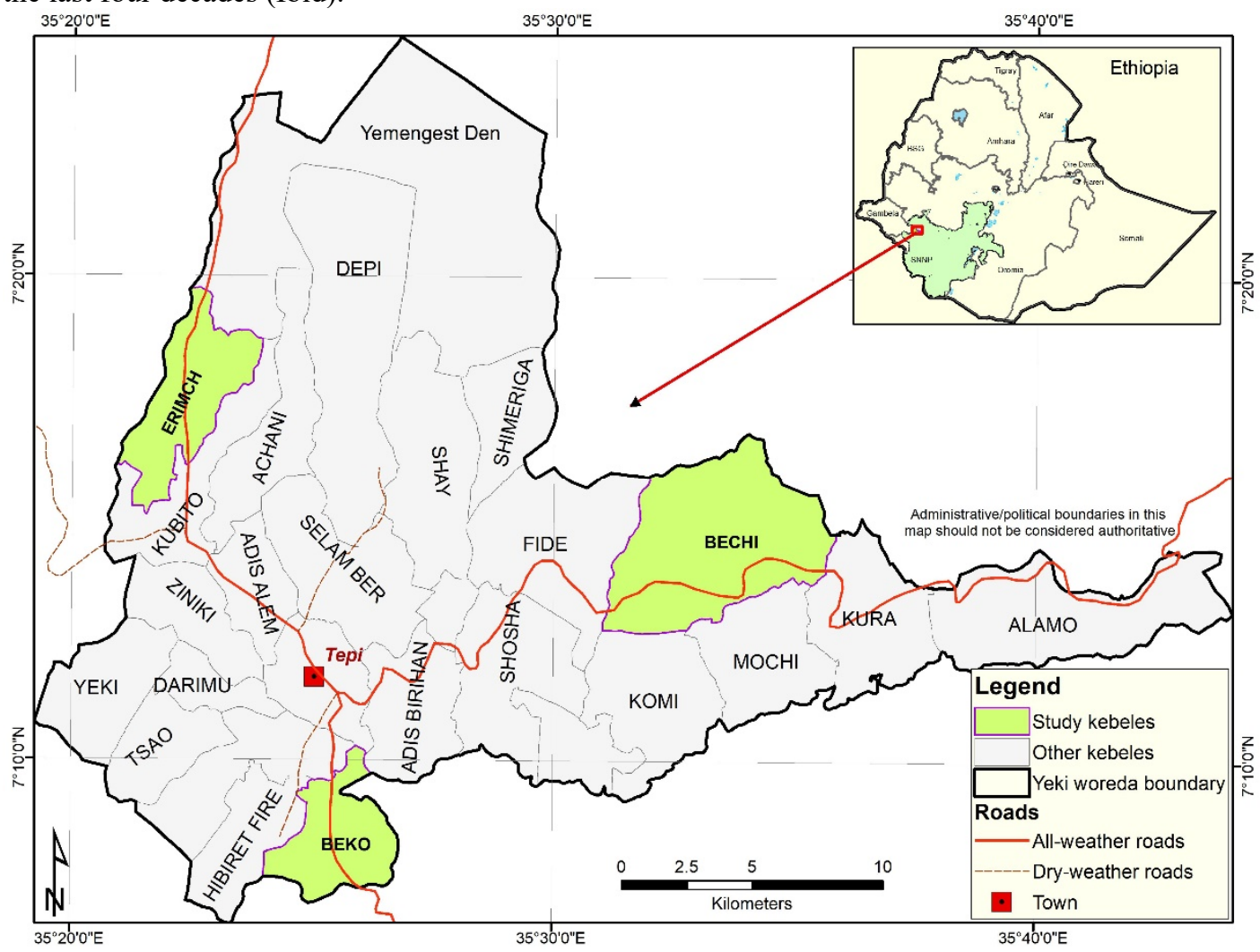

Source: Own construction, 2017

Figure 1. Map of the study area

\subsection{Sampling techniques}

Three stage sampling procedures were followed to identify the study kebeles and sample respondents. In the first stage, out of the total 22 rural kebeles in Yeki Woreda, three (Bechi, Beko and Ermich kebeles) were selected randomly because of the biophysical, socio-economic, and socio-cultural homogeneity in each kebeles. Prior to selecting the sample respondents, the list of households (sampling frame) was collected in collaboration with kebele administrators of the respective kebeles. In the second stage, male-headed households (MHH) and femaleheaded households $(\mathrm{FHH})$ were identified from the sampling frame. In the third stage, a total of 150 women households were selected from the three kebeles based on systematic random sampling procedure proportional to the size of the population in each group using the following simplified formula (Cochran, 1977).

Source: Cochran's (1977)

$$
\begin{gathered}
n=\frac{(Z)^{2} *(p)(q)}{d^{2}} \\
n=\frac{(1.96)^{2} *(0.5)(0.5)}{(0.08)^{2}}=150
\end{gathered}
$$


Where, $\mathrm{t}$ is the value for alpha level $=1.96,(\mathrm{p})(\mathrm{q})$ are the estimates of variance $=0.25$ and $\mathrm{d}$ is the acceptable margin of error $=0.08$.

\subsection{Type and Methods of Data collection}

For this study, both primary and secondary data were employed, which are quantitative and qualitative in nature. Accordingly, primary data was gathered from carefully selected women households using household survey, focus group discussions (FGDs) and Key informant interviews (KIIs). Prior to the actual survey, a pre-test was conducted on 15 non-sample respondents and necessary modifications were made on the structure of the questionnaire. On the other hand, secondary data were obtained from governmental offices and a review of published and unpublished literature relevant to the study. The type of data collected pertains to personal characteristics such as demographic, socio-economic and institutional factors of respondents, the type and choices of adaptation strategies employed to climate change, particularly on the change in rainfall and temperature of the area.

\subsection{Method of Data Analysis}

\subsubsection{Multinomial logit model specification}

When there is a dependent variable with more than two alternatives among which the decision maker has to choose (i.e., unordered qualitative or polytomous variables), the appropriate econometric model would be either multinomial logit or multinomial probit regression model. Regarding estimation, both of them estimate the effect of explanatory variables on a dependent variable involving multiple choices with unordered response categories (Greene, 2000).

However, MNP is rarely used in empirical studies due to estimation difficulty imposed by the need to solve multiple integrations related to the multivariate normal distribution (Chilot, 2007). Moreover, the MNL model was selected not only because of the computational ease, but also MNL analysis exhibits a superior ability to predict adaptation strategies and pick up the differences between adaptation strategies. In this study, therefore, a multinomial logit model specification was employed. This model makes it possible to analyse factors influencing women's households' choices of climate change adaptation strategies in the context of multiple choices. Following Green (2003), the MNL model for a multiple choice problem is specified as follows: $p_{i j}=\frac{e^{x i \beta j}}{\sum_{j=1}^{j=8} e^{x i \beta j}}, \mathrm{j}=1 \ldots . .8$

Where pij is the probability representing the ith respondent's chance of falling into category $\mathrm{j}$ or (it is the probability of household i s' choice of adaptation strategies from category $j$ ), $x i$ is predictors of response probabilities; $\mathrm{e}$ is the natural base of logarithms; and $\beta j$ is the parameters to be estimated by maximum likelihood estimator (MLE). The estimated equations provide a set of probabilities for the $\mathrm{j}+1$ choice for a decision maker with $x i$ characteristics. For the identification of the model, we need to conveniently normalize by assuming $\beta_{0}=0$ (Greene, 2003). Therefore, the probabilities are given by:

$$
\begin{aligned}
& \text { Prob. }\left(y_{i}=j / x_{i}\right)=p_{i j}=\frac{e^{x i \beta j}}{\sum_{j=2}^{j=j} e^{x i \beta j}} \text {, for } j>1 \\
& \text { Prob. }\left(y_{i}=j / x_{i}\right)=p_{i 1}=\frac{1}{1+\frac{e^{x i \beta j}}{\sum_{j=2}^{j=j} e^{x i \beta j}}}
\end{aligned}
$$

The marginal effects $(\delta \mathrm{ij})$ of the characteristics on the probabilities are specified as $\delta i j=\frac{\partial i j}{\partial x 1} p i j\left[\beta j-\sum_{j=0}^{j} p i j \beta j\right]=p i j\left[\beta j-\beta^{-}\right]$

\subsection{Description of variables and Research hypothesis}

In this study, the dependent variable was a women's choice of climate change adaptation strategy. It was identified by categorizing the sample households into adaptation strategy groups based on their choice; improved crop varieties (A), soil and water conservation practices (B) and crop diversification practices (C). However, farmers usually adopt more than one adaptation strategy at a time (Tessema et al., 2013; Kidanu et al., 2016). Therefore, the polytomous dependent variable for MNL was hypothesized to have the following values;

$\mathrm{Y}=0$, if a household does not use adaptation strategies (That is the value of $\mathrm{A}=0, \mathrm{~B}=0$, and $\mathrm{C}=0$ );

$\mathrm{Y}=1$, if a household used only improved crop variety $(\mathrm{A}=1, \mathrm{~B}=0$, and $\mathrm{C}=0)$;

$\mathrm{Y}=2$, if a household used only soil and water conservation practices $(\mathrm{A}=0, \mathrm{~B}=1$, and $\mathrm{C}=0)$;

$\mathrm{Y}=3$, if a household used only crop diversification strategies $(\mathrm{A}=0, \mathrm{~B}=0$, and $\mathrm{C}=1)$;

$\mathrm{Y}=4$, if a household used an improved variety + soil and water conservation practices $(\mathrm{A}=1, \mathrm{~B}=1$, and $\mathrm{C}=0)$;

$\mathrm{Y}=5$, if a household used improved variety + crop diversification $(\mathrm{A}=1, \mathrm{~B}=0$ and $\mathrm{C}=1)$;

$\mathrm{Y}=6$, if a household used soil and water conservation + crop diversification practices $(\mathrm{A}=0, \mathrm{~B}=1$, and $\mathrm{C}=1)$;

$\mathrm{Y}=7$, if a household used all adaptation strategies $(\mathrm{A}=1, \mathrm{~B}=1$, and $\mathrm{C}=1)$

Based on a review of different literatures and past research findings, the following potential explanatory variables 


\begin{tabular}{|c|c|c|}
\hline Variable & Description and measurement & $\begin{array}{l}\text { Expected } \\
\text { sign }\end{array}$ \\
\hline EDSTWH & Education status of the household heads ( $0=$ Illiterate, 1 Literate $)$ & $+/-$ \\
\hline SEXHHH & Sex of household head $(0=\mathrm{FHH}, 1=\mathrm{MHH})$ & + \\
\hline HHSIZ & Number of household members of woman household: Continuous & + \\
\hline LABPRO & $\begin{array}{l}\text { A Number of the productive labor force of a household whose age falls between } 15 \\
\text { and 65: Continuous }\end{array}$ & + \\
\hline WSTATUS & Wealth Status of woman household ( $0=$ Poor, $1=$ Medium, and 2=Poor) & + \\
\hline FARMEXP & Farming experience of the household in years: Continuous & + \\
\hline FARS & Total landholding within the household in hectare: Continuous & + \\
\hline EXTCONT & Contact with extension agents $(0=$ No visit, $1=$ Occasionally, $2=$ Mostly, $3=$ Regularly $)$ & + \\
\hline CCINFO & Access to climate information of woman household $(0=\mathrm{No}, 1=\mathrm{Yes})$ & + \\
\hline CREDSER & Credit service usage $(1=$ Yes, $0=\mathrm{No})$ & + \\
\hline MKTDN & The distance between a farmer's house and the nearest market in Km. Continuous & - \\
\hline OFFARM & Income from off/non-farm activities during the survey year $(0=\mathrm{No}, 1=\mathrm{Yes})$ & + \\
\hline PERCC & $\begin{array}{l}\text { Perception of a woman to climate, particularly for temperature and rainfall }(0=\text { No, } \\
1=\text { Yes })\end{array}$ & + \\
\hline WEMPO & $\begin{array}{l}\text { Level of women empowerment and inclusion in the agricultural sector: Continuous } \\
\text { taking a value from } 0 \text { to } 1\end{array}$ & + \\
\hline
\end{tabular}

Source: Own construction through literature review, 2017

\section{Result And Discussion}

\subsection{Women's Adaptation Strategies to Climate Change}

Based on the findings of the study, women households employed different farm-level adaptation measures in response to climate change in the study area over the last ten years. Accordingly, the majority of woman households (72.1\%) practised one or more adaptation strategies. The major strategies include the use of improved crop variety like early maturity and drought-resistant crops (12.7\%), use of improved crop variety and soil and water conservation practices $(12.7 \%)$, use of soil and water conservation practices and crop diversification practices (10.7\%) and all adaptation strategies (19.3\%) (Table 9).

The findings of the study were also in agreement with the response of focus group discussants as they pointed out that:

"We use different adaptation strategies depending on the size of our farmlands, the capital we had at our hand and family labor force. We use crop diversification practices in the form of intercropping mostly sorghum with haricot bean, maize with haricot bean, coffee with avocado, coffee with enset, and taro with enset. We grow sorghum and haricot bean together because as the area becomes hotter, sorghum is the most likely crop which resists it. On the other hand, sorghum provides shade for haricot bean and can grow with a little amount of rainfall. In addition, as haricot bean is an early maturing crop, the household will not starve till the other crop (like sorghum) is harvested, which will stay for six months" (Woman farmer in FGD at Bechi and Beko kebele).

On the other hand, women households practice crop diversification practice in the form of relay cropping and cultivating different crops at different farmlands to respond to the effect of changing climate particularly on temperature and rainfall. Women during the FGD argued that:

"In our kebele, it is common to see intercropping of maize with sorghum crop. Nowadays, there is no certainty about the rainfall pattern. To this end, we plant maize solely and before it reaches a stage of harvesting (mostly 1 month before harvested) we plant the other crop. Since we had a small acreage of land, this type of practice helped us to use our land efficiently in the one hand and to use the unpredictable nature of the climate on the other hand. In addition, we grow different crops in different farmlands (turmeric, rice, coffee, enset, etc.) to diversify the risks associated with the changing climate (Woman farmer in FGD, 11.03.2009 E.C).

In addition, women households practised both biological and physical methods of soil and water conservation practices. Among the biological methods, planting banana in the border of farms, trenches to divert runoff, mulching, tree planting (Gravellia, Korch, Sesa, Wanza etc.) were common in the area. On the other hand, women households practice soil bund and faniagou as a physical soil and water conservation strategies.

Thus, the result of the study was found inconsistent with the responses of the key informant interviewee as they gave evidence that multiple adaptation strategies to climate change are commonly employed by women households in the study areas. 
Table 2. Women households' choice of adaptation strategies to climate change $n=150$ )

\begin{tabular}{|l|c|c|c|}
\hline Woman's adaptation strategy & \multicolumn{2}{l|}{ Percentage of woman HH } \\
\cline { 2 - 4 } & FHH & MHH & Total \\
\hline No adaptation & 26.8 & 28.7 & 28.0 \\
\hline Improved variety & 10.7 & 13.8 & 12.7 \\
\hline Soil and water conservation practices & 3.6 & 7.4 & 6.0 \\
\hline Crop diversification practices & 5.4 & 6.4 & 6.0 \\
\hline Improved variety + soil and water conservation & 14.3 & 11.7 & 12.7 \\
\hline Improved variety + crop diversification & 3.6 & 5.3 & 4.7 \\
\hline Soil and water conservation + crop diversification & 12.5 & 9.6 & 10.7 \\
\hline All adaptation strategies & 23.2 & 17.0 & 19.3 \\
\hline Total & 100.0 & 100.0 & 100.0 \\
\hline
\end{tabular}

Source: Own survey result, 2017

\subsection{Determinants of women's choices of adaptation strategies to climate change}

The results of the MNL model indicated that different demographic, socio-economic and institutional characteristics influenced women's choice of adaptation strategies to climate change. The result further indicated that among fourteen (14) hypothesized explanatory variables, seven (7) variables were found significantly influenced women's choice of adaptation strategy to climate change in the study area. These were; productive labor force, farm size, farming experience, wealth status, access to climate information, credit service usage and extension visit.

Productive labor force: The finding indicates that as the number of the productive labor force within a household increased by one individual, the probability of implementing all adaptation strategies increases by $9.1 \%$ at less than $10 \%$ probability level. Some adaptation options are labor intensive and hence, women households with large productive labor force are more likely to share labor and as a result, reduce labor constraints to undertake each adaptation measures. This is inconsistency with the findings reported by Urgessa et al. (2014).

Farm size: The model result depicts that a one unit increment in farm size of the household results in an increase in the probability of adapting soil and water conservation practices by $0.2 \%$ and all adaptation practices by $43.09 \%$ at less than $5 \%$, and soil and water conservation practices + crop diversification practices by $11.6 \%$ at less than $10 \%$ probability level over doing nothing. Large farm size offers women households more flexibility in their decision-making process, more opportunity to take up new practices on a trial basis, and more ability to deal with risk. This result is in agreement with the results of Gebrehiwot and Van der Veen (2013).

Farming experience: Farming experience of women household had a positive and significant influence on adopting improved variety + crop diversification strategies and soil and water conservation practices + crop diversification practices at less than $5 \%$ probability level. The possible reason is that experienced women households are more likely to have more information and knowledge on the changes in climatic conditions and they can easily adjust themselves to climate change stresses. This result confirms the findings of Gbetibouo (2009), Maddison (2006) and Esiobu and Onubuogu (2014).

Wealth status: The probability of resource medium women households in adapting soil and water conservation practices is greater by $0.1 \%$ and all adaptation practices by $44.7 \%$ at less than $5 \%$ probability level than resource-poor households. Adaptation is a costly activity and those women households with better resources are able to buy new irrigation technologies and other important inputs they may need to change their practices to suit the forecasted and prevailing climatic conditions. This result confirms the findings reported by (Dasgupta et al, 2010).

Access to climate information: Women households' access to climate information increases the likelihood of using crop diversification strategy by $0.7 \%$ at less than $5 \%$, improved variety + soil and water conservation practices by $8.8 \%$, soil and water conservation practices + crop diversification practices by $19.4 \%$, and all adaptation practices by $35.7 \%$ at less than $1 \%$ significance level. Women households who had access to climate information will be conscious of the changes in climatic conditions and have higher chances of taking adaptive measures. The finding of this study is in line with the arguments conveyed by Maddison (2006) and Onubuogu and Esiobu (2014).

Credit service usage: It had positively and significantly influenced women households' choice of climate change adaptation strategies. As woman households are a customer of credit service, the probability of adapting improved variety + soil and water conservation practices increases by $49.6 \%$ at less than $1 \%$ probability level. The probable reason could be with more financial resources at their hand, women households are able to change their management practices in response to the changing climatic condition. This result is in agreement with the findings of Hassan and Nhemachena (2008) and Fosu-Mensah et al. (2010).

Extension visit: Increasing the frequency of extension visit increases the probability of women households to 
adapt improved variety by $27.9 \%$ and soil and water conservation practices by $0.1 \%$ at less than $5 \%$ and improved variety + soil and water conservation practices by $21.3 \%$ at less than $10 \%$ probability level. The possible reason could be extension service assist women households to take climate change adaptation strategies through advice and the provision of information on how to deal with climate variability and change. This observation is in line with Ndambiri et al. (2012) and Maddison (2006).

Table 4. Parameter estimates of MNL models of women' choice of adaptation strategies.

\begin{tabular}{|c|c|c|c|c|c|c|c|}
\hline \multicolumn{8}{|c|}{ Women's choice of climate change adaptation strategies } \\
\hline Variable & $\mathrm{Y}=1$ & $\mathrm{Y}=2$ & $\mathrm{Y}=3$ & $\mathrm{Y}=4$ & $\mathrm{Y}=5$ & $\mathrm{Y}=6$ & $\mathrm{Y}=7$ \\
\hline Variable & 0.840 & 2.308 & 2.280 & 0.002 & 0.525 & 0.358 & 0.014 \\
\hline Sex of HH head & 0.042 & -.0925 & -0.016 & -0.846 & -17.81 & -0.257 & -0.854 \\
\hline Education status & 0.054 & -0.069 & 0.025 & 0.050 & $.165 * *$ & $\begin{array}{r}0.118 \\
* *\end{array}$ & 0.076 \\
\hline Farming experience (year) & -0.026 & -0.054 & -0.032 & 0.141 & -0.407 & 0.002 & -0.181 \\
\hline Household size (number) & -0.065 & 0.882 & -0.224 & 0.046 & 0.012 & -0.235 & $0.454 *$ \\
\hline productive labor force (number) & -0.641 & $9.230 * *$ & 0.802 & 1.232 & 2.04 & $2.22 *$ & $2.807 * *$ \\
\hline Farm size $(\mathrm{ha})$ & 0.255 & $8.008 * *$ & -3.015 & -1.484 & -20.03 & -0.576 & 4.744* \\
\hline Resource-medium & 18.663 & 0.360 & -1.533 & 14.183 & -5.03 & 15.09 & 12.292 \\
\hline Resource-rich & -0.006 & -0.365 & 0.089 & 0.056 & 0.217 & -0.068 & 0.198 \\
\hline Market distance $(\mathrm{km})$ & $1.802 * *$ & $4.222 * *$ & -0.914 & -0.577 & -0.576 & 1.319 & 0.70 \\
\hline $\begin{array}{lll}\begin{array}{l}\text { Occasionally } \\
\text { extension agent }\end{array} & \text { visited } & \text { by } \\
\end{array}$ & -0.589 & -15.61 & 1.730 & 2.187* & -0.850 & 0.367 & -1.037 \\
\hline $\begin{array}{l}\text { Mostly visited by extension } \\
\text { agent }\end{array}$ & -16.786 & -18.57 & -15.36 & 1.701 & -15.17 & -15.1 & -15.37 \\
\hline $\begin{array}{l}\text { Regularly visited by extension } \\
\text { agent }\end{array}$ & -1.4276 & 2.613 & 0.606 & -0.349 & 0.597 & 0.002 & -0.843 \\
\hline Off-farm income & -0.079 & -1.92 & 1.465 & $2.686 * * *$ & -1.37 & -0.359 & -0.545 \\
\hline Credit service usage & 1.3 & -0.572 & $\begin{array}{r}3.637 \\
* *\end{array}$ & $2.877 * * *$ & 1.42 & $4.86 * * *$ & $4.265 * * *$ \\
\hline Access to climate information & -0.977 & -0.232 & 1.091 & -0.077 & 0.73 & -0.607 & -0.792 \\
\hline $\begin{array}{l}\text { Perception to temperature and } \\
\text { rainfall }\end{array}$ & -0.0428 & -0.433 & -2.537 & 0.537 & 0.194 & -0.474 & -0.036 \\
\hline Cons & -2.53 & -14.16 & -5.57 & -6.303 & -4.27 & -8.330 & -6.76 \\
\hline $\mathrm{N}$ & 150 & 150 & 150 & 150 & 150 & 150 & 150 \\
\hline
\end{tabular}

\section{Source: own source survey, 2017}

Note: $* * *, * *$ and $*$ are level of significance at less than $1 \%, 5 \%$ and $10 \%$ level respectively.

$\mathrm{Y}=0$ (No adaptation), $\mathrm{Y}=1$ (Improved variety), $\mathrm{Y}=2$ (Soil \& water conservation), $\mathrm{Y}=3$ (Crop diversification), $\mathrm{Y}=4$ (Improved variety + Soil \& water conservation), $Y=5$ (Improved variety + crop diversification), $Y=6$ (Soil \& water conservation + crop diversification) and $\mathrm{Y}=7$ (All adaptation practices) 
Table 5. Marginal effects from the MNL models of women' choice of adaptation strategies.

\begin{tabular}{|c|c|c|c|c|c|c|c|}
\hline Variable & $\mathrm{Y}=1$ & $\mathrm{Y}=2$ & $\mathrm{Y}=3$ & $\mathrm{Y}=4$ & $Y=5$ & $Y=6$ & $Y=7$ \\
\hline Sex of HH head & 0.138 & 0.0003 & 0.013 & -0.053 & $5.12 \mathrm{e}-07$ & 0.010 & -0.058 \\
\hline Education status & 0.111 & -0.0001 & 0.003 & -0.092 & -0.0011 & 0.011 & -0.107 \\
\hline Farming experience (year) & -0.0001 & $-2.3 \mathrm{E}-05$ & 0.000 & -0.001 & $2.19 \mathrm{e}-07$ & 0.006 & 0.005 \\
\hline Household size (number) & -0.001 & $-6.1 \mathrm{E}-06$ & 0.000 & 0.034 & $-7.60 \mathrm{e}-07$ & 0.002 & -0.039 \\
\hline $\begin{array}{l}\text { productive labor } \text { force } \\
\text { (number) }\end{array}$ & -0.037 & 0.0001 & -0.002 & -0.007 & $-1.34 \mathrm{e}-07$ & -0.030 & 0.091 \\
\hline Farm size (ha) & -0.416 & 0.002 & -0.001 & 0.050 & $2.06 \mathrm{e}-06$ & 0.116 & 0.439 \\
\hline Resource-medium & 0.334 & 0.001 & -0.008 & -0.083 & -0.0001 & 0.027 & 0.447 \\
\hline Resource-rich & 0.834 & -0.0004 & -0.017 & -0.146 & $-6.12 \mathrm{e}-06$ & -0.053 & -0.207 \\
\hline Market distance $(\mathrm{km})$ & -0.015 & -0.0001 & 0.000 & 0.001 & $3.24 \mathrm{e}-07$ & -0.011 & 0.035 \\
\hline $\begin{array}{l}\text { Occasionally visited by } \\
\text { extension agent }\end{array}$ & 0.279 & 0.001 & -0.012 & -0.251 & $-2.34 \mathrm{e}-06$ & 0.062 & 0.026 \\
\hline $\begin{array}{l}\text { Mostly visited by extension } \\
\text { agent }\end{array}$ & 0.005 & -0.003 & 0.040 & 0.213 & $-4.18 \mathrm{e}-07$ & 0.123 & -0.087 \\
\hline $\begin{array}{l}\text { Regularly visited by } \\
\text { extension agent }\end{array}$ & -0.280 & -0.0002 & -0.008 & 0.674 & $-2.12 \mathrm{e}-06$ & -0.102 & -0.262 \\
\hline Off-farm income & -0.181 & 0.002 & 0.011 & 0.048 & $3.03 \mathrm{e}-06$ & 0.060 & -0.061 \\
\hline Credit service usage & -0.129 & -0.0004 & 0.006 & 0.496 & $-3.33 e-06$ & -0.070 & -0.218 \\
\hline $\begin{array}{l}\text { Access to climate } \\
\text { information }\end{array}$ & -0.199 & -0.0006 & 0.007 & 0.088 & $-1.34 \mathrm{e}-06$ & 0.194 & 0.357 \\
\hline $\begin{array}{l}\text { Perception to temperature } \\
\text { and rainfall }\end{array}$ & -0.114 & 4.13E-05 & 0.019 & 0.087 & $3.46 \mathrm{e}-06$ & -0.014 & -0.075 \\
\hline Women empowerment(5DE) & -0.019 & -0.0001 & -0.018 & 0.107 & $3.21 \mathrm{e}-07$ & -0.048 & -0.016 \\
\hline & & $\begin{array}{l}\text { ase categor } \\
\text { Jumber of o } \\
\text { R chi2(119) } \\
\text { rob > chi2 } \\
\text { og likelihoc } \\
\text { seudo R2 }\end{array}$ & ervations & 0.375 & $\begin{array}{l}\text { No Adapta } \\
150 \\
213.48 \\
0.0000 \\
-177.9331\end{array}$ & on $(Y=0)$ & \\
\hline
\end{tabular}

\section{Source: Own survey results, 2017}

$\mathrm{Y}=0$ (No adaptation), $\mathrm{Y}=1$ (Improved variety), $\mathrm{Y}=2$ (Soil \& water conservation), $\mathrm{Y}=3$ (Crop diversification), $\mathrm{Y}=4$ (Improved variety + Soil \& water conservation), $\mathrm{Y}=5$ (Improved variety + crop diversification), $\mathrm{Y}=6$ (Soil \& water conservation + crop diversification) and $\mathrm{Y}=7$ (All adaptation practices)

\section{Conclusions And Recommendations}

For rural women households in Yeki woreda, farming is not only a way of life, but it is also a means of livelihood. However, they have been affected by the impacts of climate change through the reduction of yield, the occurrence of human diseases and the reduction of water sources. In order to improve the ability of women households to adjust to the ongoing and future climate change, the need to understand their adaptation strategies at the local level is important. From the findings of this study, that the majority of women households employed a variety of farmlevel adaptation practices. Among these, the use of improved varieties like early maturing and drought resistant crops, a combination of the use of improved varieties and soil and water conservation practices (both biological and physical conservation practices), diversification of crops in the form of intercropping and growing different crops at different farmlands.

A range of factors influences women households choice of climate change adaptation strategies. Among these, farming experience, farm size, wealth status, access to climate information, credit service usage and extension visit influence choice of adaptation strategies of women significantly and positively in the study area. In some cases, a wide range of institutional and technological support enhanced the local adaptation strategies of women households in the study area. Labor saving technologies, for example, played an important role to reduce their labor constraints and thereby respond to the consequences of climate change. Moreover, ensuring affordable credit schemes for women households is important as this helps them increase their ability and flexibility to different adaptation strategies in response to the changing climate. On the other hand, local agro-meteorological stations should be established to the level that they are efficient in providing reliable, trustworthy weather forecasts pertinent for women households. The role of government, NGOs and other responsible bodies is, therefore, imperative in improving women households' level of awareness on adaptation strategies through training and making the extension services (climate-related information and advice) more accessible to women households. 


\section{Acknowledgement}

The authors express special thankfulness to the Ethiopian Institute of Agricultural Research (EIAR) for funding the research. Many thanks and appreciation goes to Mr. Awoke Endrie, Mr. Aschalew Bekele, Mr. Kedir Jemal and $\mathrm{Mr}$. Adane Teshome who have administered the questionnaires, tolerating the hardship of moving from one farmers' home to that of others. I am grateful, to the 150 woman respondents who have spared their precious time to respond attentively to the questionnaire, without which this report could not have been documented.

\section{References}

- Chilot Yirga. (2007). The dynamics of soil degradation and incentives for optimal management in the central highlands of Ethiopia. PhD Thesis, University of Pretoria, South Africa.

- Cochran, W.G. (1977). Sampling techniques, 3rd.Edition. New York, John Wiley and Sons.

- CSA (Central Statistics Agency). (2007). Summary and statistical report of population and housing census, Addis Ababa, Ethiopia.

- Dankleman, I. 2010. Gender and climate change: An introduction, Earth scan, London.

- Dasgupta, A. and Baschieri, A. (2010). Vulnerability to climate change in rural Ghana: Mainstreaming climate change in poverty reduction strategies. Journal of International Development, 22(6): 803-820.

- $\quad$ Deressa, T.T., Hassan, R.M., Ringler, C., Alemu, T. and Yesuf, M. (2009). Determinants of farmers' choice of adaptation methods to climate change in the Nile basin of Ethiopia. Global environmental change, 19(2): 248-255.

- Fosu-Mensah, B. Y., Vlek P. L. G. and Manschadi, A. M. (2010). Farmers' perception and adaption to climate change: A case study of Sekyedumase District in Ghana, Centre for development research, University of Bonn. ISSN 0081-4539.

- Gbetibouo, G. (2009). Understanding farmers' perception and adaptations to climate change and variability, the case of the Limpopo Basin, South Africa: IFPRI Discussion paper 00849. Limpo basin, South Africa.

- Getachew Shiferaw. (2012). The gender dimension of climate change and women's role in environmental protection and natural resource management in South Wollo, Ethiopia.

- Green HW. 2003. Econometric Analysis, 4th Edition, New York University, Macmillan Publishing Company.

- Hassan, R., and Nhemachena, C. (2008). Determinants of African farmers' strategies for adapting to climate change: Multinomial choice analysis. Centre for Environmental Economics and Policy in Africa, University of Pretoria. AfJARE, 2 (1): 83-104.

- IFAD (International Fund for Agricultural Development). (2010). Climate change impacts, South Asia, http://www.ifad.org/events/apr09/impact/seasia.pdf (last access:18 March 18, 2017).

- IPCC (Intergovernmental Panel on Climate Change). (2014). Impacts, adaptation and vulnerability: Global and sectoral aspects. Contribution of working Group II to the fifth assessment report of the intergovernmental panel on climate change, United Kingdom and New York, US.

- Kibria, G. 2016. Why are women in developing countries more vulnerable to Climate Change? Climate change implications on women with reference to food, water, energy, health, and disaster security. Technical Report. New Delhi, India. 10p

- Maddison, D. (2006). The perception and adaptation to climate change in Africa. CEEPA Discussion Paper No. 10, Special series on climate change and agriculture in Africa. ISBN 1-920160-01-09.

- Mer (Netherlands commissions for environment). (2015). Climate change profile of Ethiopia. Dutch sustainability unit; fact sheet.

- $\quad$ Ndambiri K, Ritho C, Mbogoh G, Ng'ang'a I, Muiruri J, Nyangweso M, Kipsat J, Omboto I, Ogada O, Kefa C, Kubowon C, Cherotwo H. (2012). Analysis of farmers' perception of the effects of climate change in Kenya: the case of Kyuso district. Journal of Environment and Earth Science, 2(10): 74-83.

- Onubuogu, GC and NS Esiobu. (2014). Trends, perceptions and adaptation options of arable crop farmers to climate change in Imo State, Nigeria: A multinomial logit model approach. World Journal of Agricultural Sciences, 2 (5): 108-122.

- Ragasa, C. (2012). Improving gender responsiveness on agricultural extension. In: A. R. Quisumbing, R. Meinzen-Dick, T. L. Raney, A. Croppenstedt, J., A. Behrman and A. Peterman (ed.), Gender in agriculture and food security: Closing the knowledge gap. Amsterdam.

- Tessema YA, Aweke CS, Endris GS. (2013). Understanding the process of adaptation to climate change by smallholder farmers: the case of east Hararghe Zone, Ethiopia. Journal of Agriculture and Food Economics, 1 (13): 1-12.

- $\quad$ TNSRC (Tepi National Spices Research Center). (2015). National spice research strategy for spice plants: Tepi, Ethiopia.

- USGS, USAID and FEWS NET. (2012). A climate trend analysis of Ethiopia. Fact Sheet, 2012-3053. 
- Wiersum, K. F. 2010. Forest dynamics in southwest Ethiopia-interfaces between ecological degradation and resource enrichment. PP: 323-342. In: F. Bongers and T. Tennigkeit (Ed.), Degraded Forests in Eastern Africa. Management and Restoration.

- Ziervogel G., Nyong, A. Osman, B. Conde, C. Cortes, S. and Dowing T. (2006). Climate variability and change: Implications for household food security. Assessments of impacts and adaptations to climate change: Working Paper No. 20, Washington DC, USA. 